\title{
GLOBALIZACIÓN Y LA CRISIS EN EL DERECHO: REPENSANDO LA ÉTICA Y LA MORAL EN EL ESTADO PÓS-MODERNO
}

DENDASCK, Carla ${ }^{1}$

SILVA, Adonías Osias ${ }^{2}$

DENDASCK, Carla; SILVA, Adonijah Osias-globalización y la crisis en el derecho: Repensando la ética y la moral en el estado posmoderno - conocimiento multidisciplinario científico Core Magazine Vol. 1. Año. 1. Marzo. 2016, pp: 98-119ISSN: 0959-2448

\section{RESUMEN}

Esta prueba tiene como objetivo un análisis crítico sobre la globalización económica y tecnológica y su impacto en el derecho positivo, con su lógica normativista de cara formal los contextos cada vez más complejo y cambiante. A partir de esta premisa, se pretende evaluar cómo la ética y la moral puede servir de norte en este cambio de paradigma que es necesario para una aplicación de la ley que mejor satisfaga las aspiraciones del ciudadano en una sociedad en constante cambio. El objetivo es analizar el papel del derecho en este nuevo sesgo de la globalización y su importancia para el hombre moderno.

Palabras clave: ética. Moral. Globalización. Derecho

1 Doctorado en psicoanálisis, posdoctorado en psicoanálisis clínico, Máster en Bioética y Director del centro de investigación y estudios avanzado-correo electrónico: prof.dra.csd@hotmail.com.

${ }^{2}$ Abogado, postgrado en derecho tributario; Maestría en derecho en la Escola Paulista de Direito; Adonias.Silva@UNIFESP.br. 


\section{INTRODUCCIÓN}

Es sabença de la General que la trayectoria del hombre en el planeta, a partir de las cuevas hasta el homo sapiens, cuando el hombre comenzó a tomar conciencia de su inteligencia y hasta su libertad para superar los obstáculos que siempre se cruzaron en su camino, siempre ha estado marcada por la participación en la construcción del derecho y la justicia.

Incluso en los albores de la civilización, cuando no había una idea de mejor derecho y la justicia lo tiene en la actualidad, el hombre siempre ha luchado para ser el protagonista de su propia historia y dentro de esta canción se convirtió en un político y moral, que actuaban dentro de su concepto de la ética y la moral.

De hecho, se puede distinguir al hombre de otros seres vivos exactamente para su desarrollo intelectual, que a su vez está directamente relacionada con su conducta en la sociedad, es decir, en su procedimiento moral se demuestra a través de sus actitudes en convivencia colectiva con sus compañeros, que no sucede con la otra viven seres que actúan sólo por instinto. Que su posición entre las otras máquinas automotrices de la naturaleza es da una posición prominente como dominador social (REALE, 1994).

Desde las costumbres sociales transmitidas de padre a hijo las relaciones de los grupos sociales han evolucionado desde simples paradigmas de convivencia hasta la estructura de mando más sólida como la ley de positivado y como consecuencia de la eminentemente gregario del ser humano de su convivencia social exsurgir la derecha, como un fenómeno social de su propia cultura con sus normas y sanciones.

Y para ratificar esta realidad existe un principio Latino que dice: "ubi societas, ibi ius est" (donde hay sociedad, allí será a la derecha). Este es el punto de partida de esta prueba, ya que la sociedad ha evolucionado, se ha convertido en global, y el derecho positivo con sus regulaciones formales, parece, ya no puede satisfacer las aspiraciones de este hombre moderno que en un mundo globalizado sigue en su eterno viaje en busca de justicia. 
Globalización, que vino de la mano con la revolución tecnológica y los cambios económicos, después de que ganara su primera fase de la instalación, que es la integración de los mercados mundiales, ahora nos presenta un nuevo reto son las ramificaciones y el impacto en las instituciones jurídicas. El gran desafío es saber que la eficacia y el alcance de las instituciones legales e instrumentos jurídicos para esta nueva realidad del hombre globalizado.

Al lado de eso, no hay que olvidar el papel de la ética y la moral en el derecho moderno, bases para una sociedad justa y correcta. Este hecho puede verse por el simple hecho de que, en la práctica, la aplicación práctica de la ley se hace a través de la justicia distribuida para un hombre - el juez - que el sistema jurídico se encuentra con el Honorable mister para resolver la controversia entre las partes en conflicto en busca de una frase.

Al comparar el proceso procesal en busca de la oración lo que te das cuenta de se colocan en el enfrentamiento no sólo legal, sino a todos los principios éticos y morales que la ley procesal requiere no solo los litigantes, así como su propio juez. El punto es cómo ser ético en degenerada corrupción traída dentro de la globalización y sus sistemas tecnológicos, donde pueden malversar de una simple elección de liquidador de condominio hasta una elección para elegir a nuestros gobernantes.

Globalización económica impone el deber del hombre ser Rico, tener, poseer a toda costa y las innovaciones tecnológicas son las pistas que conducirán a la locomotora de la deshonestidad, bajo el pretexto de van los extremos justifican los medios, más lejos y los seres humanos de valores éticos y morales que recibió desde la cuna. $Y$ en este sistema la nexted "Ley de Gerson", de la facilidad a cualquier costo, es la ley, con todos sus aspectos y determinantes.

Se trata de la crisis en el derecho a tratar en este texto, teniendo en cuenta los aspectos de la globalización, que ha hecho del mundo una aldea global y tomó con él los valores de la ética y la moral transmitida a nosotros por nuestros padres fundadores. Vivimos hoy en contextos cada vez más complejos y mutable, que claman 
por una ley contextualizada que responda a las necesidades actuales del hombre, que no son el mismo hombre insertado en el contexto del siglo pasado.

Qué puede decirse del concreto es que el estado y la ley, siguiendo el modelo tradicional nos implantamos en la sociedad hoy en día, no adaptado a la evolución social experimentada por los seres humanos dentro de la sociedad. Hoy más que nunca, el derecho debe tomar otras direcciones si desea responder a las aspiraciones de este hombre. El derecho tiene que recurrir a medios alternativos, es decir, la ley debe ser un derecho de negociación, de mediación, arbitraje y mesas redondas.

Lo cierto es que los caminos que nos trajeron ahora no será el mismo que nos llevará de ahora en adelante. Y de esta realidad es válida para analizar hasta qué punto el derecho positivado, con una lógica formal y rígido, puede cumplir la satisfacción de las aspiraciones de este hombre globalizado, en particular en cuanto a los aspectos éticos y morales. Hay que mantener la ética y la moral sin perder de vista de la ley y su correcta aplicación al caso concreto.

\section{GLOBALIZACIÓN EN EL ESTADO MODERNO}

La historia ha demostrado que el hombre siempre ha luchado por mejoras en sus condiciones de vida. Conglomerados humanos ya tomaron la forma de ciudades alrededor del 3500 A.C. y su contexto social surgieron los guerreros con sus primitivas armas fueron forjadas por la defensa del grupo social. De esto se presentó los constructores de la mansarda, que dominaban el uso del agua, y quienes, con su sabiduría aprendió a interpretar fenómenos naturales y se convirtieron en sus sacerdotes y jueces.

De ese desarrollo principal hombre y la sociedad evolucionó de diferentes maneras y en varias etapas, que no quieren aquí, analiza desde este papel no se presta a este desideratum. Sin embargo, cabe señalar aquí sólo el abolutismos que marcaron los inicios del estado moderno, que trajo como una característica el monopolio del uso de la violencia por los déspotas, que manera absoluta tenía el poder a toda costa, no que sólo los legisladores pero también juez de su propia voluntad. 
El estado, con el fin de mantener la paz social amenazado o violado, prohibió la autotutela y pidió responsabilidad resolver los conflictos. Desde ese momento el estado tiene ahora la función de aplicar la ley a los casos específicos presentados y solución del conflicto.

Como resultado el estado como titular de la orden, ley y justicia restringiendo el campo de los gobernantes a los límites estrictos de la ley, dando al poder judicial la competencia exclusiva para juzgar y resolver conflictos y esto lo hace a través de la jurisdicción. La jurisdicción de la palabra viene de la composición de dos palabras: el sustantivo Latino jus, juris, que significa "derecha", más la tercera Conjugación el verbo dicere, que significa "decir", "decir", "expreso". Así, la jurisdicción es el poder que el estado tiene que decir el derecho.

Sin embargo, la jurisdicción es inerte, según el principio Latino: "nemo iudex $t$ y el seno; NE procedat iudex officio de t (no hay juez sin actor; el juez deberá de oficio). Por lo tanto, el arte. 2 del código de Procedimiento Civil, que así prolata: "ningún juez proporcionará la protección judicial si no como parte o interesada en aplicar, en los casos y las formas jurídicas".

Por esta razón, para que el estado pueda ofrecer el rendimiento y ejercer su papel como mediador de conflictos no es necesario que el titular de los conflictivos intereses en la relación jurídica material de derecho tiene iniciativa y van llamando a las puertas del poder judicial. Por caso, es válido destacar que aunque el estado tiene la competencia para iniciar, una vez causada la función jurisdiccional del estado, el proceso será desarrollado por oficial impulso hasta su finalización con una sentencia que puso fin al acuerdo.

Con el crecimiento de la población y el crecimiento económico, tecnológico y social, la demanda de ciudadanos golpeando en las puertas del poder judicial son proporcionalmente más grandes que las respuestas dadas a aquellos que buscan una respuesta a sus demandas y conflictos. Y el resultado de esto es que el poder judicial, que ya no cumple con las exigencias allí tomadas, un activismo judicial que no corresponde a las preocupaciones de los ciudadanos. 
Hoy en día, con la globalización, los problemas que enfrenta la sociedad son completamente diferentes a las de hace una generación y la tendencia es un aumento de estas dificultades, y la certeza que tenemos es que el poder judicial no está preparado para los cambios que se presentan a la próxima generación, que analizaremos en las siguientes líneas.

Cuando se trata de lo que la globalización tiene en mente es un análisis serio de los procesos interrelacionados y cambios que están ocurriendo en el escenario mundial y con él la manera de pensar, actuar y vivir en la sociedad entera está cambiando sustancialmente. Estos cambios afectan no sólo las estructuras económicas y sociales que interfieren directamente en la producción legal actual y, consecuentemente, en la forma de pensar y de hacer el derecho.

El primer punto que usted no puede dejar de mencionar es la cuestión de la soberanía del Estado-nación ante el crecimiento de multinacionalismo y transnacionalismo. Con el ascenso de corporaciones multinacionales y el surgimiento de agentes supranacionales y transnacionales rampantes traídos por la globalización, el estado de la nación considera que su fuerza mitigada en lo relativo a la regulación y estructuración de regulaciones económicas, así como sobre la protección del individuo y de la sociedad. Lo que antes era competencia exclusiva del Estado nación, de la globalización será el objetivo y el interés de otras instituciones transnacionales y multinacionales.

Las empresas multinacionales, con su capacidad de expansión, tanto de la producción y otras operaciones alrededor del mundo, a pesar de su importancia para el desarrollo económico y social, imponen el derecho de una manera diferente de pensar traída moldes del siglo pasado y se ha perpetuado en la historia. La facilidad con que estas empresas tienen que trasladar sus fábricas de un país a otro, así como su potencial mundial de comercio, que requiere el derecho de tener una visión general y más abierto y menos sistemática, cerrado y ubicado como el actual.

La importancia de estas empresas para la economía mundial conduce a un cambio de enfoque a las relaciones sociales, con toda su complejidad, requieren el abogado no 
sólo la perspectiva nacional, sin embargo, una mirada "más allá de las fronteras', es decir, una mirada global. Hasta que se convirtió en lugar común si escuchas que "el mundo es una aldea global," lo que significa que las cercas, muros y las fronteras que nos separan de nuestros vecinos, ahora ya no puede ser vislumbrada.

Tal realidad afecta el derecho de todos los niveles y sus desarrollos en valores éticos, comportamiento moral y las bueno que se requiere de los ciudadanos en este contexto social globalizado. Expuesto a todos los riesgos provocados por la globalización, este ciudadano, que una demanda judicial ante su demanda, no encontrará la derecha más que conceptos e institutos, formalmente y determinado, que no puede satisfacer sus necesidades dentro de esta complejidad global.

Por esta razón, podemos decir que puntos de la globalización a un cambio en los negocios civiles, penales, administrativos y, sobre todo, el derecho internacional, es necesario adaptarse constantemente a nuevas e inusuales situaciones que hasta hace algún tiempo se pensaba que existen, como el comercio mundial y financiero los mercados Unión que, a pesar de su flexibilidad para crear capital unido a nivel mundial y la facilitación de la libre circulación de inversión sin fronteras, una nueva realidad y difusa a la ley actual.

Otro factor que debe considerarse en este mundo globalizado es el tema del crecimiento de bloques económicos regionales, ya que afecta directamente el modus operandi de la derecha como es en nuestra sociedad. Qué es más común hoy en día y ha aumentado cada año, es el intercambio entre los bloques comerciales regionales, a saber, la reducción de las barreras comerciales entre las Naciones. Sólo recuerde a siglas como ALCA, MERCOSUR, UEA, sólo por nombrar algunos de estos bloques que se unen con afinidades comerciales. Lo cierto es que hoy en día el comercio internacional es una realidad y los conceptos neoliberales que eran más hegemónica, están abriendo las puertas de muchos países anteriormente cerrados al diálogo, como es el caso de Europa del este, la ex Unión Soviética y, con reflejos positivos en China.

El libre comercio internacional y el énfasis exacerbado que los mercados privados de alguna manera descentraliza y reduce el papel del gobierno, que siempre ha sido el 
regulador de la economía. Este cambio en el comercio libre de esos paseos que influencia directamente la política económica del "Tío Sam", así como la política económica europea en General, para la creación de entidades como el FMI, el BIRF (así como los bancos regionales y GATT) y se propaga sus efectos en el mundo globalizado.

Y si todos estos cambios no fueran suficientes para dibujar el gráfico de la sociedad actual, todavía puede hablar sobre la tendencia mundial a la democratización, la protección de los derechos humanos, un interés mucho mayor en el campo del derecho, dada la función jurisdiccional del estado inicialmente señalado. Paralelo a las manifestaciones evidentes de cambios económicos, un enorme esfuerzo a nivel internacional, para la creación de políticas liberales, que tienen por objeto proteger los derechos humanos del individuo, así como el control del arbitraje y el fortalecimiento de las instituciones jurídicas que petición judicial realmente vienen a ofrecer a los ciudadanos, frente a sus intereses difusos y colectivos.

Paralelo a esto usted también encontrará las ONG que son actores transnacionales y supranacionales, que aparecen en este escenario con el fin de proteger los derechos humanos, los derechos de los desfavorecidos, el derecho a un medio ambiente sostenible, los derechos de los pueblos indígenas, los derechos de las minorías, la cuestión de lo afectivo en la sociedad, homo sólo para nombrar algunos de ellos. No hay que olvidar que todos estos temas forman parte de la vida cotidiana de los ciudadanos y la sociedad espera una respuesta satisfactoria y se llega a encontrar que el hombre moderno que, al parecer, le pidieron a salir de la cueva, sin embargo no tuvo los medios para avanzar, razón por la cual aún absorta a todo lo que ves a tu alrededor sentirse impotente y no está preparado para enfrentar esta nueva realidad.

Para analizar todo este problema mundial es la ley de patentes ha esforzado en la fontanería y conducción de los conflictos y enfrentamientos han surgido dentro de la sociedad, razón por la cual se debe hablar no sólo en un radical y urgente, en una total adecuación de los conceptos tradicionalmente utilizado, en tal manera que, en la misma forma que el hombre salió de la cueva el derecho también hacer de la misma manera y llegar a encontrar que el hombre moderno en medio de una sociedad 
caótica, un mundo globalizado y una experiencia de conflictos generalizados en todos los niveles.

\section{DERECHO POSITIVISTA Y LÓGICA FORMAL}

No es posible hablar de positivismo en el ámbito jurídico sin remolque a la figura de Hans Kelsen. De hecho, aunque se considera al padre del positivismo cabe destacar que todo ab initio doctrina positivista era construido en los años y tuvo su principal papel en el desarrollo del derecho como ciencia.

Para Kelsen, la ley debe entenderse como norma, divorciado de cualquier diseño social o evaluativa. Creo que sólo de este modo la pieza central de su obra, conocida como teoría pura del derecho, la versión de que la ciencia jurídica a todo el contenido, por la óptica de Kelsen, no es suyo. Proponiendo eso fractura el jurista alemán pretende dar autonomía jurídica ciencia propia, totalmente libre de elementos que no pertenecen a ellos.

Para Kelsen la ciencia jurídica pura debe ser inconfundible a psicología, sociología, política y moral. Aunque tales Ciencias se relacionan de alguna manera a la derecha y cruzan su camino la mayoría de las veces, sin embargo, la ciencia jurídica no impregnada de conceptos fuera de su área de especialización. Tal comprensión, aunque suene extraño a los oídos, tiene su valor cuando se quiere hablar de justicia, como si se utiliza un lenguaje preciso y rígido lógica, Kelsen resumieron derecho concepto la idea de justicia.

La justicia es siempre y siempre estrechamente vinculado con los valores (siempre variables) adoptados por quien invoca (ya sea por discusiones sociológico, psicológico o moral), no siendo un concepto de ley universal válida, debido a la inexactitud y la fluidez de significado, hacer lo correcto para un determinado contexto o sociedad que no sería justa a otro.

En la visión de Joram el derecho se limita a un conjunto de reglas representado por la categoría de requisitos "debe ser" y de tal modo trae los hechos a una escala jurídico 
o antijurídico. Con eso uno se da cuenta claramente que Kelsen crea una ética basada en la distinción entre ser y debe ser. En otras palabras, Kelsen distingue entre cómo las cosas son y deberían ser las cosas y esta relación entre "ser" y el "deber-ser" termina en dos aspectos distintos, y que son cruciales en su diseño. El primero de estos aspectos se relaciona con el hecho de que esta distinción entre ser y deber-ser sirve para distinguir entre dos formas en las que uno puede estudiar derecho: la primera es la visión del derecho como es, y la segunda es la vista de la ley como debe ser. El segundo aspecto que esta distinción también sirve para hacer un hito divisorio entre el Reino de hechos relacionadas con ser- y el Reino de las normas-deben estar relacionadas con. Por lo tanto, la ecuación siguiente: el incumplimiento de la obligación (la ausencia de hecho), implica sanción (debe ser). En palabras más claras: la falta (derecho), debe haber una pena (sanción establecida por la norma).

En este contexto, Kelsen señala que la norma es un producto de la voluntad, elaborado con el propósito de regular la conducta humana y que sirve como una interpretación. Aquí es necesario destacar que para el positivismo al estándar no tiene ninguna validez para el sentido de ser justo, pero por el simple hecho de estar conectado a otra norma que se considera superior llama norma fundamental. Es desde este concepto metodológico de la norma fundamental que el jurista puede crear una sistematización de un ordenamiento jurídico todo.

Uno de sus conceptos teóricos prácticos más de gran envergadura es la idea de sistema jurídico como un conjunto interconectado de normas jurídicas estructuradas en forma de una pirámide abstracta, puntuada y dominada por la Constitución del estado, que hace las otras normas jurídicas de inferior jerarquía (las diversas leyes infra-constitucionales y otras actas normativas). Esta concepción teórica es que extractos del concepto de rigidez constitucional, que permiten y requieren un sistema para proteger la integridad de la Constitución. Aunque existen controversias acerca de la creación de la pirámide normativa, con el propósito de este ensayo se atribuye a Kelsen.

Otra importante contribución del jurista en el mundo práctico de la ley era la Constitución de Austria de 1920, redactada bajo su inspiración. A la sombra de la 
influencia de Kelseniano pensado esta carta política austríaca, marketing anterior derecho positivo innovado el concepto de control concentrado de la constitucionalidad de las leyes y normativa actúa como función judicial por una corte constitucional, cargado con la función exclusiva de la integridad de la Constitución.

De allí la jurisdicción constitucional puede ser dividida en dos partes: la jurisdicción constitucional (control concentrado de constitucionalidad) y difuso de la jurisdicción constitucional (control difuso de constitucionalidad). Este último modo de protector de la Constitución (difusa) ya era practicada en los Estados Unidos de América.

En el sistema legal brasileño, bajo los auspicios de la Constitución Federal de 1988, la jurisdicción constitucional se practica ambas formas: concentrado, a través de acciones de la competencia de la Corte Suprema y el difuso, ejecutado en los registros de cualquier acciones (y los recursos a estos inherentes) dentro de la jurisdicción de cualquier corte, si los jueces o tribunales.

Por lo tanto, cuando se habla de Kelsen nos no podemos perder de vista el tema principal de su pensamiento que es la validez de la regla de derecho y de su jerarquía, siendo este uno de los aspectos más importantes de su teoría.

Antes de la anterior uno puede ver la ley positivista es un conjunto de normas que rigen la conducta humana y estas normas, a su vez, cuando falta válida y legítimamente percibida adquirir poder establecer sanciones, debido a su estructura, se caracteriza por ser un orden coactivo y que sólo se aplica si usted está vinculados umbilicalmente a otro estándar.

El gran problema que se presenta en relación con el positivismo legal es que a pesar de es un sistema de reglas que rigen la conducta del hombre en sociedad, pero la rigidez del positivado correcto no puede satisfacer las preocupaciones de que el hombre mismo. Esta caminadora es digno de mencionar la crítica hecha por Dworkin al positivismo jurídico en decir que el positivismo es tan dogmático que "la ley a menudo se convierte en lo que dice el juez" (DWORKIN, 2003, p. 4). Esta crítica de Ronald Dworkin hace contrapunto a la ley positivista que muestra un modelo teórico 
que está destinado a dar una respuesta adecuada a la cuestión de la interpretación, que él llama la integridad de la ley

Bien, este dogmatismo intolerante del positivismo jurídico, que en última instancia reducir la ley la declaración de ciertos jueces que está teniendo la esperanza de los ciudadanos, relegando a la derecha sólo para el mundo de las ideas, lo que debería ser y no el mundo real, lo que se espera cuando se introdujo en el poder judicial con una demanda: la concreción de la demanda. No hablo aquí de la justicia, porque como se ha mencionado, el positivismo jurídico no tiene ese reclamo a la justicia, sino simplemente tiene como objetivo proporcionar un concepto universalmente válido de la ley, aparte de otras realidades sociales. El punto aquí es que al menos el tan ansiado efecto de tomar prestación jurisdiccional de hecho y de derecho y no sólo teoría en disposiciones legales, verbalizados por toga.

\section{ÉTICA Y LA MORAL EN EL DERECHO}

Cuando se trata de la ética y la moral en el derecho de uno no puede dejar de mencionar que la conducta de un individuo en relación con el otro, en cada contexto social en peleas judiciales, llevado a cabo a la justicia, siempre tiene un fuerte sesgo moral.

La única diferencia entre los postulados éticos y morales y la derecha es que este último tiene su fuerza coactiva regulado por el ordenamiento jurídico, que todos superpuestos con sus normas y estándares definidos, que dicta trae consigo responsable las sanciones a que presente.

El jurista positivista Hans Kelsen (2001:36), ya mencionado en este texto, aporta una importante contribución a la comprensión de este tema ética y moral en el derecho. En su obra "Qué es la justicia", el erudito alemán así se expresa:

Reconociendo el derecho como la técnica coercitiva específica de orden social, nos podemos comparar con otros órdenes sociales que, en parte, persiguen los mismos objetivos que la ley, pero por diferentes medios. La ley es el medio social específico, 
no un fin. La ley, la moral y la religión - los tres prohiben el asesinato. Pero la ley hace tan proporcionando que: Si un hombre comete asesinato, otro hombre, señalado por la ley, se aplica contra el asesino, cierto grado de coacción prescrito por el ordenamiento jurídico. La moralidad simplemente requieren: no matarás.

Cabe destacar que aunque la moral tiene no el poder y la fuerza para establecer una sanción por su desobediencia, como lo hace la derecha, todavía no puede ser descuidado por los estudiosos del derecho, desde antes el derecho positivado con sus normas morales y conceptos ya fue utilizado por las sociedades primitivas como un medio para orientar y conducir las relaciones en la convivencia social.

Por lo tanto, la distinción entre el principio moral y jurídico es una línea muy fina y a menudo van juntos y siguiente y que están separados sólo por sus efectos. Nos toma como ejemplo un hijo que al pasar por su padre y recibe un halago no intercambió la misma cortesía, o incluso distrae, tal comportamiento es una ofensa moral para la que hay un dolor legal. Sin embargo, si este mismo hijo, para ser recibido por su padre provoca una lesión personal, en este caso comete delito previstas en el planeamiento y debe ser castigado.

Por esta razón, Chaïm Perelman (1996:289), el gran filósofo de Bruselas y uno de los más grandes filósofos del siglo XX. XX, para abordar este tema y la ley moral, a la izquierda los siguientes inscritos:

Tradicionalmente, insisten en estudios dedicados a las relaciones entre derecho y moral, en un espíritu kantiano, en lo que la distingue: el derecho regula el comportamiento; la moral hace hincapié en la intención, la ley establece una correlación entre los derechos y obligaciones, los deberes Morales prescriben que no dan lugar a derechos subjetivos, la ley establece las obligaciones sancionadas por el poder; la moraleja sanciones organizada se escapa. Abogados disconformes con una concepción positivista, estadísticas y formalista, insisten en la importancia del elemento moral en el funcionamiento de la ley, en el papel que juegan la buena fe, mala fe, intención maliciosa, la moralidad y tantas otras nociones cuyo aspecto ético no puede ser despreciado. 
Por las palabras del filósofo, erudito de Bruselas ya puede tener una idea de lo que moral y ética en la aplicación de la ley hasta la actualidad. Vivimos en una sociedad donde la ética y la moral valores a ser confundido con los intereses personales y privados, razón por la cual estos valores son cada vez más relegados a un segundo plano, señas de identidad de una sociedad de consumo, donde lo que importa es alcanzar los objetivos, independientemente del medio utilizado para ello, que el viejo principio prevalece que los fines justifican los medios.

Porque es exactamente en esa fina línea entre los valores morales y éticos y moralidad que el derecho debe andar su camino, una vez que la empresa viene perdiendo estos valores en cada generación. En la época de nuestros padres la palabra simple había sellado legal y negocios fue continuado hasta circunstancias.

En la actualidad, incluso cuando rodeado por todas las garantías, valores y todo, pero tienes la garantía real de que el negocio jurídico va a venir a término de forma, sin la intervención del estado ejercer su papel a coator requieren las reglas inicialmente compactuadas.

En este requisito social que se impone en el derecho actual, la forma se materializa en el proceso, a través de la decisión del juez, trae toda la colección de la cultura humana en los intereses de los litigantes ante el Tribunal del estado, que toma cada vez más su papel por la sociedad de coator del delegado.

Lo cierto es que en comparación de la práctica del procedimiento son traídos a la confrontación no sólo normativa sino también todos los principios éticos que la ley del proceso de demanda de los litigantes e incluso el juez mismo. Flanqueado de libertad hay una estructura entera de la lealtad y sinceridad que es requerido por la ley en el cares y lazos judiciales. Lo que usted debe obtener no es sólo la norma positivada y formal, pero también valores éticos y morales como elementos esenciales de la demanda solicitó revisión judicial.

La forma está organizada la sociedad hoy en día, con todos los instrumentos de control social y el aumento de información a través de la tecnología y el crecimiento 
económico a causa de la globalización, ya no se presta a un mero espectador de la justicia. Por el contrario, falta el marco legal ha demostrado, más que nunca, lo que se observa hoy en día, es una sociedad tratando de tomar la ley en sus manos, tratando de llenar el vacío dejado por el poder judicial sobre la responsabilidad judicial, pero lamentablemente operan al revés, lo que, a menudo bajo el manto de la justicia, la injusticia todavía más. Todo esto de este formalismo jurídico, que busca sólo en la técnica y la mejora de las respuestas a los problemas sociales, es claro que este modelo no está soportado por la sociedad moderna las leyes.

Ya que es válido tener en cuenta aquí las palabras del jurista italiano Francesco Carnelutti (2004:60) que tiene: "Si la ley es un instrumento de justicia, no la técnica o la ciencia suficiente para manejarlo". Se evidencia por las palabras del ínclito jurista italiano la aplicación práctica del derecho, que lo hace por justicia llevó a cabo en conflictos legales, requiere algo más que técnicas legales y estándares de administración de justicia. La gran pregunta que no puede ocultar es que si la aplicación directa como se hace estos días, positivado, listo y formal, visa realmente justicia. Uno puede ver que la aplicación de los problemas prácticos que el poder judicial no son respuesta antes de los conceptos jurídicos previamente establecidos y estrictamente formal.

No fue sin razón que Jhering (2012:322) dijo que los problemas prácticos no se adaptan bien al que paraíso de los conceptos en que muchos abogados prefieren vivir. Según João Maurício Adeodato (2012:317), propone una interpretación menos dogmática de Jhering, autor que es internacionalmente considerado como uno de los más importantes para la dogmática del derecho privado.

Dado que uno se da cuenta de que la ley debe andar en busca de un equilibrio entre el positivista visión normativista de Hans Kelsen, donde la decisión del juez debe ser formada por la posta (derecho positivo por lo tanto) y la posición más extrema

propuesto por la tópica Viehweg, para que la decisión no debe tener relación con los textos reglamentarios. En este sentido, João Maurício Adeodato (2012:313) escribe con mucha propiedad sobre el tema: 
Viehweg tópica parece conducir a una «abierto» excesivos en relación con el texto reglamentario, que se considera sólo una tapas de expresión entre otros. Niega la conexión necesaria del postulado dogmático texto, tópicos hacen que la "orientación por medio de" un método demasiado libre y está a punto de los poderes de decisión.

Qué pasa si intento rescatar este dogmatismo del derecho positivo busca sólo y tan sólo que el estándar establecido por el estado su apoyo base, en detrimento de los argumentos morales y éticos en la búsqueda de justicia. Lo que es de mayor importancia es el sistema jurídico actual, estatalmente positivado y regirán por sus propias reglas extremadamente formales.

Como corolario de este escenario formal y rígido, que ya no satisface los deseos del hombre moderno es que la alternativa de solución de controversias, tales como mediación, arbitraje, conciliación, que retratarse como adjuntos al poder judicial para intentar hacerlo. Tales institutos llevar en su seno no sólo una alternativa a la tradicional forma de resolver conflictos, pero una búsqueda y rescate de los valores éticos y morales que se manifiestan en la acción de árbitros y mediadores.

En el escenario de estos institutos nuevos que surgen en nuestra sociedad es que debe brillar como la conducta de un abogado profesional, su ética y su postura moral frente a la crisis que aparecen cada vez más discutible argumento de prueba. Por otra parte tiene el derecho del cliente que patrocina; por otra parte, como un adversario, la respuesta de la otra parte, que también tiene su abogado patrono.

Es en este contexto que el abogado ejerza su ardua tarea en intelectuales de la defensa de su cliente, sin embargo, permaneció de pie y en consonancia con su creencia en el derecho a defensa y justicia buscando, sin olvida los valores éticos y morales que condujeron su formación hasta la actualidad, es decir, todo su ética y moral patrimonio que se estaba formando en el curso de su carrera terrenal. 


\section{ÉTICA Y LA MORAL EN LA REALIZACIÓN DE LA JUSTICIA}

Una vez analizado la relación entre ética y moral, la ley es válido dirección al otro lado de la moneda, que es la ética y la moral en la ejecución de la justicia. Si el derecho positivado, como es hoy en día, busca sólo el estándar controlados por el estado y rígidamente formal, sin tomar en cuenta los valores éticos y morales y la moral establecida por la sociedad, merece la pena hacer una seria reflexión sobre la contribución de la ética y la moral en la realización de la justicia.

Se sabe que el objeto 's moral ética. La moral de la palabra deriva del Latin, significa "costumbres", que, a su vez, es la parte de la ciencia que se encarga de, moral esencial a la vida social del hombre. Es el conjunto de reglas para la conducta humana como virtud. Por lo tanto, la moral es indispensable para el contenido del derecho, especialmente cuando se trata de ejecución de la prestación jurisdiccional, que tiene lugar por medio de la justicia.

La ciencia de los deberes se conoce como ética y los principios axiológicos que regularlos, no ética. Según el distinguido jurista Miguel Reale: "la ética es la ciencia de normas". Sólo el ser humano posee este legado, que difiere de otros seres vivos, que como ya se mencionó al principio de este texto.

Es válido aquí las palabras de José Renato Nalini (1997:30), que es conocido como uno de los más importantes teóricos del estudio de la ética en el Brasil, que expresa:

La ética es la ciencia del comportamiento moral de los hombres en la sociedad. Es una ciencia porque tiene objeto propio, sus propias leyes y método propietario. El objeto de la ética moral. La moraleja es uno de los aspectos del comportamiento humano. La expresión deriva de las costumbres romana palabra con un sentido de las costumbres, reiteró el conjunto de normas adquiridas por hábito de su práctica.

Por lo tanto, uno puede asumir que la ética es la ciencia que estudia los actos de conducta humana en el contexto social basado en la lealtad y la decencia, en suavidad de actos y en la dignidad de la postura, para que la búsqueda de la verdad es el 
objetivo mayor a ser alcanzado, por encima de los personales y los intereses creados de las pasiones. Lamentablemente, lo que se observa es que los intereses personales han superado los valores morales y éticos y el verdadero deseo de justicia, y es esta situación que ya no se puede sostener en este globalizado y la sociedad de la información.

Lo que no puede ser olvidado es que el ética se convierte, en este contexto, un requisito previo para vivir una vida justa en esta sociedad globalizada. Sin ética es insoportable la vida en sociedad y la lealtad, que es su principal virtud, debe no sólo guía la relación, pero to se convierten en el núcleo de su esencia.

No es sin razón que el estudio de la ética trata sobre miles de años y la edad y es motivo de preocupación para la antigua Grecia y la erudición clásica, cuyas contribuciones deben ser considerados hasta hoy cuando se trata de tema moral y ética.

Usted puede, simplemente a modo de ejemplo, el nombre Aristóteles9, quien admitió en una edad joven como discípulo de Platón (quien a los 41 años fue designado por Filipo de Macedonia a tutor de Alejandro el grande) y fuente inagotable de sabiduría humana, dedicada a su hijo Nicómaco, nacido del segundo matrimonio de Herpile de Stageira, una de sus obras sobre ética que todavía hoy se publica en cualquier parte del mundo.

Según Robison Barone (2012:23), en la cartilla de ética profesional de su abogado, cita el estagirista como sigue: "... esto no es estudio teórico como los otros, porque estudiamos no para saber lo que es la virtud, pero para ser buena, que de lo contrario no haría usted bien" (Libro Il de la ética a Nicómaco).

Aún así, Miguel Reale (1994:24), otro importante jurista de la escena nacional, enseña que Aristóteles, en el octavo libro de la ética a Nicómaco, desarrolla su teoría de la justicia y dice:

... el adjetivo de injusto se aplica a dos tipos de individuos: 1) para aquellos que desobedecen la ley; 2) para aquellos que quieren recibir más de su parte, es decir, la 
parte que por ley debe concederse. En contraste, la feria es lo que obedece a la ley y lo que está contento con su parte.

No pudo evitar pero recuerda el ilustre Baruch Spinoza (2010), o Bendictus Spinoza, como él mismo solía firmar sus escritos, que también molestaban con este tema de la ética, desarrollando un estilo hermético, desde la definición de Dios, a través de los caminos en busca de la libertad del alma el poder de la razón.

Hay, por lo tanto, por las palabras de estos nobles pensadores, que la ética tiene su papel predominante en la aplicación de la ley y en la búsqueda de la justicia. En teoría, se desvincularon de práctica ha obstaculizado y golpeó el curso de la justicia durante los años. Vale la pena reiterar lo que se ha hablado sobre la complejidad de los problemas que están surgiendo en esta sociedad globalizada.

Lo cierto es que la historia del mundo está siendo escrito en una velocidad vertiginosa y acelerada, a diferencia de generaciones pasadas, donde los avances se dieron los pasos lentos y tenía las condiciones adecuadas hasta cierto punto, para sostenerse y responder adecuadamente a las preocupaciones de los ciudadanos.

Hoy en día, con el avance de la ciencia, los nuevos descubrimientos en el campo genético, milagros y aterrador crecimiento de internet, vida generados en los laboratorios, la clonación de seres humanos, la longevidad de la vida, el flujo de noticias, la fascinación con la computadora y la epidemia de los teléfonos móviles, el hombre moderno ya no tiene la misma certeza que sus antepasados. Ahora todo es relativo: la transmuda hoy en ayer en la velocidad de un átomo.

Dentro de que todo desarrollo y tecnología de vanguardia, lo único que el hombre no, hasta ahora, era la fórmula mágica de la solidaridad, el respeto por el otro hombre, no el depredador de la naturaleza peor y más cruel. Lamentablemente, para desencanto esta humanidad, que encanta con tecnología de punta y los grandes descubrimientos y avance de la ciencia, el terror se convirtió en la postura ética del otro, que actúa ferozmente como un animal sin sentido, no sólo extranjero, sino también ley usurpar si rabiando contra aquellos que quieren proteger tales intereses. 
En este contexto, se entiende que la moral y la ética es actores clave para el rescate de esa sociedad corrompida y dispuesto por ley y la justicia. Hoy más que nunca, existe una necesidad urgente para la rehabilitación de la ética en nuestra sociedad para que al hombre volviera a su dignidad. Las formas de violencia, egoísmo, orgullo e indiferencia por sus similares, son los fundamentos de la pérdida de la moral y la ética. No es suficiente reconocer la dignidad de la persona humana en el acto normativo, si la conducta personal experimentado en la sociedad se ha guiado por ella.

Lo cierto es que la ética y moral, una vez redimida, serán propulsores y conducir a un futuro de esperanza y promesa para la humanidad, que aunque ante tanta tecnología y desarrollo, ha convertido las prácticas mezquinas y primaria, que los hombres más lejos de la convivencia social que integran. Este es el gran reto para las sociedades modernas, este es el papel de la ética en este umbral del tercer milenio.

\section{LA IMPORTANCIA DEL DERECHO PARA EL HOMBRE MODERNO}

La relevancia que el derecho desempeña en la crisis estructural de la sociedad moderna trata fulcralmente, diseminada y expresa descortinamos en nuestro país que termina por generar una cadena de las reacciones más adversas es rampante. La falta de valores morales y éticos empiezan por gobernantes que, en vez de dar ejemplo de suavidad y de probidad, prefieren seguir el camino opuesto, anclado bajo el manto de la impunidad, que el ciudadano que paga sus impuestos se rebelan y luchan por mantener una vida decente y correcto. Para otro cambio, algunos ciudadanos consternado por esta situación deciden actúan del mismo modo, bajo la lógica eso si el error proviene de allí de ninguna razón para no actuar del mismo modo.

Este panorama de anarquía y el caos es que los ciudadanos se enfrentan en su día a día y no se cansa de preguntar hasta cuándo seguirá viendo todo este poder, sin perspectivas de cambios, en un sistema legal que, con su compleja serie de estéril, las leyes no pueden crear tal ciudadano los mecanismos de defensa que mantiene la estructura del estado con sus impuestos pesados no retorno concreto. Lo cierto es que la posibilidad o la perspectiva de cualquier cambio en este estado de cosas debe 
pasar a través de la consideración de grave y urgente de los institutos jurídicos y su aplicación en la sociedad, que ha dejado mucho que desear en la prestación jurisdiccional.

Hay mucho material escrito sobre este tema, y la tendencia en el tiempo es el que más juristas y estudiosos del derecho hacia atrás, sus ojos a este problema, en el sentido de un cambio de dirección de las direcciones que ha tomado el derecho, no sólo en nuestra sociedad pero, por qué no decirlo, del mundo en su conjunto, es decir, la falta de respeto a los intereses del ciudadano que busca justicia, en detrimento de esta corrupción rampante que rabia y deshonra al poder judicial, exactamente por meros intereses personales.

Para el jurista Lênio Streck (2009) el derecho no puede llenar esa brecha en nuestro ordenamiento jurídico, que perpetúa la política de la impunidad y la falta de preparación de los jueces de no responder a las aspiraciones de los ciudadanos, no por falta de previsión en el sistema jurídico, si no por lo que él llama una "crisis". Qué propone el jurista Gaucho es implementar un cambio de paradigma desde el modelo legal actual en nuestra sociedad, que está muy lejos de la realidad actual en nuestro país.

Es exactamente esta "crisis" por el jurista de separador de agua de Rio Grande que llevará a cabo la conducta de los abogados en esta sociedad globalizada y compleja. Los viejos crímenes tan disgustado por la moral del hombre de la cavernas primitiva vuelve ahora a estar comprometidos con una crueldad mayor. Añadir a otros delitos de nuestra generación, como los delitos electrónicos como la clonación de tarjetas de crédito, Banco saldos movimiento criminal a través de balanzas electrónicas, enviar correos electrónicos mendaz con enlaces que tratan de capturar las contraseñas para fines delictivos, entre otros que sólo la mente humana es capaz de tejer y ejecutar.

Bueno, es dentro de ese contexto caótico y desordenado que encontramos la importancia de la ley para el hombre moderno, porque el derecho, en su búsqueda de justicia, es el centro de la consideración de todos estos problemas que el hombre moderno. Desde los dramas personales de derecho de familia con su frío salud, hasta 
la inmovilidad absoluta de algo que podamos hacer frente a la masacre de vidas inocentes a manos de un "Punisher" caido loco y sediento de venganza, la derecha debería ser reconsiderada seriamente para contemplar los males sociales que el hombre moderno en completa perplejidad e impotencia frente a hechos presencia cada día en la sociedad.

La relevancia de la derecha si ve en la involución de la sociedad moral con la conducta de los gestores públicos, que Excel para hacer la ley un instrumento de su voluntad, contra los intereses de los gobernados torpes e ineptos al enfrentarse a este problema. El derecho debe resound de los intereses personales e ideológicos y si arrojas la búsqueda de este cambio de escenario que ahora se presenta.

El imperio de la fuerza bruta ha sido lo que ha prevalecido en nuestra sociedad. En el tratamiento con infracción de los derechos de los platos de la balanza de la justicia nunca oscilan para el ciudadano ante el estado, mucho menos a favor de los pobres hacia los más ricos, o incluso antes de los privilegiados contra un anónimo.

Para ser un concepto claro de lo que se habla, las reglas de procedimiento civil establecen privilegios a favor de la entidad pública, con quad para defenderse a sí mismo y al doble, y hemos mencionado que el estado sí mismo-juez, en la persona del juez, puede apelar contra su propia decisión, cada vez se emite contra el estado.

Y para empeorar las cosas, las reformas judiciales propuestas en nuestra sociedad nunca a favor del ciudadano litigante; por el contrario, todas las reformas en Brasil se ha vuelto contra el litigante, en un vano intento de tratar de convencer a sociedad que la justicia es lenta y que el retraso en la prestación judicial revisar no sólo del poder judicial sí mismo.

Este data del momento actual que estamos viviendo, que es una insaciable búsqueda de rehabilitación de la ética y la moral en el mundo, de tal manera que una norma mínima de conducta en los actos de la vida en sociedad y, en el caso de la justicia, en todo lo que refiere a los derechos del ciudadano. Abogados, jueces, fiscales, todos 
juntos deben ser constructores de una nueva realidad jurídica, en la búsqueda constante de valores éticos y morales en pos de la justicia.

Institutos de solución alternativa de conflictos como los ya mencionados, mediación, conciliación y arbitraje, son bienvenidos en esta reconstrucción de proceso y la búsqueda de justicia, puesto que no reclamar a la substitución del poder judicial, sino que viene como elenco de apoyo de esta búsqueda de algo nuevo y que, de hecho, llenan en los ideales de justicia olvidado y dejado de lado a lo largo de la historia.

\section{CONCLUSIÓN}

Antes de todo lo que fue dicho, el derecho tiene que abandonar esta dogmática y cerrada si se asume que en el momento y debe caminar hacia una más plural. En este mundo globalizado, con todos los filamentos han señalado, no hay más espacio para una visión rígida y unívoca y extremadamente formal, por el contrario, se puede hablar ahora en multiplicidad de actores sociales (abogados, jueces, psicólogos, técnicos) y el pluralismo de los institutos legales que mejor se adapte a las preocupaciones que la sociedad moderna, incluyendo el arbitraje, la mediación y la conciliación.

El momento actual conduce a la sustitución de la individualización de la función del juez en un proceso de corresponsabilidad de otros actores involucrados en el proceso colectivo de cambios sociales (los actores fuera de la judicatura, como el retromencionados de pros), todos Unidos en busca de una solución sólida, palpable y concreta a las necesidades del hombre actual. El poder judicial debe promover y facilitar la producción de experiencias que promuevan la conexión entre sí mismo y la sociedad en lugar de separación, fragmentación y lejanía del ciudadano de su anhelo de justicia.

En esta nota, el poder judicial se debe fomentar alianzas y armonización de las prácticas legales con los institutos ya mencionado que si sabes por experiencia, ha sido capaz de dar una vuelta más adecuada y satisfactoria al ciudadano. No debería existir aquí tiene miedo de la competencia, mucho menos el temor de parecer contradicciones que pueden llegar a surgir en medio de este proceso de cambio. Las 
contradicciones deben ser trabajadas y no eliminadas, ya que aunque algunos de ellos pueden parecer a priori, insuperable, sin embargo no deben permanecer paralizadas o fugas y la historia de la ciencia se hace de la construcción y deconstrucción de paradigmas y la superación de las paradojas.

Por lo tanto, para cualquier cambio es necesario para que el poder judicial a abrir la producción de experiencias que fomenten la multiplicidad de conocimientos y prácticas jurídicas, alentando a la sociedad, incluso entre diferentes perspectivas y teorías de la actual "status quo". Debe existir la búsqueda de diálogo con los 'movimientos sociales' y otros actores que deconstruyen las formas tradicionales y burocratizadas de participación ciudadana en su propia historia.

Hoy, más que nunca, hay una necesidad urgente de entender que ese papel político y legal está jugando los retos que se presentan hoy al hombre moderno (o posmoderno) y darse cuenta de que toda producción de trabajo a cambio estructural tiene consecuencias sociales, o mejor dicho, que toda la producción proviene de ciertos cambios y múltiples relaciones de poder y campos de fuerza.

La caminata al proceso de cambio, para el sentido crítico y potencial transformador, depende de la labor del poder judicial de la autoevaluación crítica sobre el significado y las consecuencias de su forma de actuar. Es necesario para las prácticas legales se basan en la interacción con las necesidades sociales, con los retos de la globalización, siempre haciendo un contrapunto con la situación actual de la justicia, que es desguazada y no hay condiciones mínimas para satisfacer las aspiraciones de los ciudadanos, demandas excesivas en su lugar hay la cara.

Por esta razón, el poder judicial tiene que reconocer y legitimar otros actores que están dispuestos a contribuir a la solución de los conflictos y la satisfacción del ciudadano. En lugar de la cuestión del conflicto de competencia que el poder judicial debe actuar para sentarse a la mesa con los otros profesionales en sintonía con las necesidades vitales del hombre, más allá de los problemas señalados y las diferencias que observó. Que sería un paso de gigante hacia un cambio de ética política, inductor y conductor de la reflexión dirigido a no solo una autocrítica, pero también un verdadero cambio 
que pretende poner el derecho en su verdadero camino, que es la búsqueda de la justicia en un mundo globalizado, sin olvidar la ética y moral y las pilastras de una sociedad democrática guía genuina basada en el estado de derecho.

\section{REFERENCIAS BIBLIOGRÁFICAS}

ADEODATUS, João Maurício. Ética y retórica. 5ㅗㄹ edición. São Paulo: Saraiva, 2012. , João Maurício. Legitimación por el procedimiento legalmente organizada: notas sobre la teoría de Niklas Luhmann. En: Ética y retórica: hacia una teoría de la dogmática jurídica. p. 53-80, São Paulo: Saraiva, 2002.

BARONI, Robison. Cartilla y abogado de ética profesional. $3^{\stackrel{a}{ }}$ ed. LTR Editora Ltda:

BOBBIO, Norberto. Positivismo jurídico: lecciones de la jurisprudencia. Traducido por Márcio Pugliesi, Edson Bini, Carlos e. Rodrigues, São Paulo: icono, 1995.

. Teoría general de la política. Traducción de Daniela Beccaccia Versiani, Rio de Janeiro: Campus, 3. Reimpresión, 2000.

. Teoría del ordenamiento jurídico. 10. Ed. Traducción de dos de Maria Celeste cordero leche Santos, Brasilia: Ed. Universidad de Brasilia, 1997.

Francesco CARNELUTTI. Lo que dio a luz a la derecha. Traducción de Ricardo Rodrigues gama. $1^{\circ}$ Ed. Campinas: Editora Russel, 2004.

DWORKIN, Ronald. El imperio del derecho. Martins Fontes: São Paulo, 2007. P. 4

Faria, José Eduardo, el derecho y la globalización económica, las implicaciones y

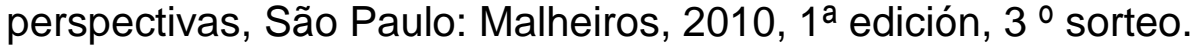

Fernández Jr., introducción al estudio del derecho: técnica, decisión, dominación. 3. Ed. São Paulo: Atlas, 2001. 
HIJO, Willis Santiago guerra. Teoría de la ciencia jurídica. 2 Ed. Sami: São Paulo, 2009.

HABERMAS, Jürgen. Derecho y la democracia: entre facticidad y validez. 4. Ed. vol. 1. Traducción de Flavio Beno Sienbeneichler, Rio de Janeiro: Brasil tiempo, 1997. v 3.

Rudolf Von JHERING. La lucha por el derecho. Martin Claret: São Paulo, 2003.

KELSEN, Hans. El problema de la justicia. 2. Ed. Traducción de João Baptista Machado, São Paulo: Martins Fontes, 1996.

. Qué es la justicia-la justicia, la ley y la política en el espejo de la ciencia. $3 \stackrel{\text { a }}{ }$ ed. São Paulo: Martins Fontes, 2001.

. Teoría general del derecho y del estado. 3. Ed. Traducción de Luís Carlos Borges, São Paulo: Martins Fontes, 1998.

. TEORÍA PURA DEL DERECHO. Traducir João Baptista Machado. ed 6. São Paulo: Martins Fontes, 1999, Página 1.

NALINI, José Renato. Ética general y profesional. Rvista de tribunales: São Paulo, 1997.

Nunes, Pedro. Diccionario de tecnología Legal. ed 13. Renovar: Río de Janeiro, 1998.

Chaïm Perelman. Ética y derecho. Martins Fontes: São Paulo, 1996.

REALE, Miguel. Una nueva ética para el juez. Coord. José Renato Nalini. Revista de los tribunales: São Paulo, 1994.

SPINOZA, Baruch. La ética. Trad. Lívio Xavier. Ed. Tecnoprint S.a.-Ediouro: São Paulo.

VALLE, Gabriel. Étiva y derecho. 1 ํㅡ. Síntesis editorial: São Paulo, 1999. 
SETHI, Paul Vincent. Normas de ética profesional. Legal editorial Ltda: fortaleza, 1989.

, Eugenio Raul ZAFFARONI-estilo salta. Poder judicial, crisis, éxitos y malentendidos. Trad. De Juárez Tavares. Ed. Revista de los tribunales: São Paulo, 1995. 